\title{
Lossy/lossless coding of bi-level images
}

\author{
Martins, Bo; Forchhammer, Søren
}

Published in:

Data Compression Conference, 1997. DCC '97. Proceedings

Link to article, DOI:

10.1109/DCC.1997.582116

Publication date:

1997

Document Version

Publisher's PDF, also known as Version of record

Link back to DTU Orbit

Citation (APA):

Martins, B., \& Forchhammer, S. (1997). Lossy/lossless coding of bi-level images. In Data Compression Conference, 1997. DCC '97. Proceedings IEEE. https://doi.org/10.1109/DCC.1997.582116

\section{General rights}

Copyright and moral rights for the publications made accessible in the public portal are retained by the authors and/or other copyright owners and it is a condition of accessing publications that users recognise and abide by the legal requirements associated with these rights.

- Users may download and print one copy of any publication from the public portal for the purpose of private study or research.

- You may not further distribute the material or use it for any profit-making activity or commercial gain

- You may freely distribute the URL identifying the publication in the public portal

If you believe that this document breaches copyright please contact us providing details, and we will remove access to the work immediately and investigate your claim. 


\section{Lossy/Lossless Coding of Bi-level Images}

\section{Bo Martins and Søren Forchhammer \\ Dept. of Telecommunication, 371, Technical University of Denmark e-mail: bm@tele.dtu.dk and sf@tele.dtu.dk}

We present improvements to a general type of lossless, lossy, and refinement coding of bi-level images [2]. Loss is introduced by flipping pixels. The pixels are coded using arithmetic coding (either QM-coding or that of [1]) of conditional probabilities obtained using a template as is known from JBIG and proposed in JBIG-2 [2]. Our new state-of-the-art results are obtained using the more general free tree [1] instead of a template. Also we introduce multiple refinement template coding. The lossy algorithm is analogous to the greedy 'rate-distortion'-algorithm of [2] (distortion is the fraction of pixels flipped) but is based on the free tree:

1) Find the free tree [1] and encode it. 2) Collect image statistics for all contexts. 3) List flip candidates. 4) Evaluate flip candidates and possibly flip them. 5) Losslessly encode the altered bitmap.

Steps 3 and 4 (optionally repeatable) specify the flipping of pixels, thus defining the lossy image. The process may be stopped at a specified target rate $r *$ or distortion $d *$. Based on the tree counts for the entire image we calculate a marginal change in total rate $(\delta r(i))$ that will result from flipping an individual pixel $i$. These calculations are done by summing the marginal changes of the statistics counters of those contexts that are affected by the flipping. The contexts involved are not as easily found as is the case for template coding.

$N$-step multiple refinement coding takes a lossy image to the lossless image in $N$ passes. Refined image no. $i$ is generated with a template [2] coder that has template pixels in the causal part of refined image no. $i$ and template pixels in the non-causal part of refined image no. $i-1$. For multiple refinements we make use of an overlay image with pixel values, $j$, in the set $1 \cdots N$, specifying that the corresponding binary pixel is to be considered for refinement coding/decoding in refinement pass no. $j$ only. The overlay image is constructed from the initial lossy image by an algorithm known to encoder and decoder. One possibility is to use the probability estimate of the least probable symbol of the initial coding. If $2^{-(j+1)}<p_{L P S} \leq 2^{-j}$ then the value of the corresponding pixel in the overlay image is $j$.
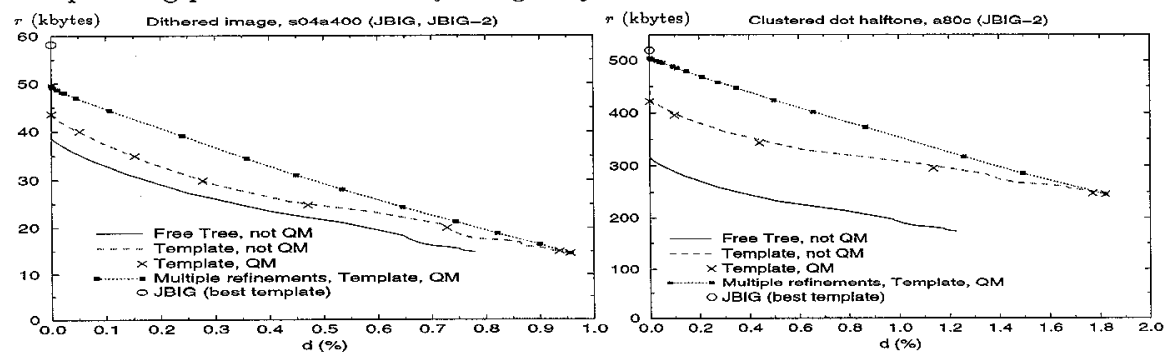

\section{References}

[1] B. Martins and S. Forchhammer. Bi-level Compression with Tree Coding. In Proc. of Data Compression Conference, pages 270-279, 1996.

[2] B. Martins and S.Forchhammer. Lossless/Lossy Compression of Bi-level Images. Accep. to IS\&T/SPIE Symp. on Electr. Im.: Science and Technology 1997, 1996. 